\title{
Occupational Health and Safety Management Systems in Small and Medium Enterprises in Asaba, Delta State, Nigeria
}

\author{
Article by Ufuoma Aduh ${ }^{1}$ Mike Enemuwe, ${ }^{2}$ Obehi Hilda Okojie ${ }^{3}$ \\ ${ }^{1}$ Department of Public Health, Ministry of Health, Asaba, Delta State, Nigeria. \\ ${ }^{2}$ Department of Community Medicine, Delta State University Teaching Hospital, \\ Oghara, Delta State, Nigeria. \\ ${ }^{3}$ Department of Community Health, University of Benin, Benin City, Edo State, \\ Nigeria. \\ Correspondence: \\ Dr. U. Aduh \\ Email: aduhufuma@yahoo.com
}

\begin{abstract}
Background

SMEs in Nigeria serve as the catalyst for employment generation, poverty reduction and economic development. Therefore studies on occupational health services in SMEs are needed to improve the occupational health and safety services in small and medium enterprises.

Objective

To assess and compare the occupational health and safety management systems between small and medium enterprises in Asaba, Delta State, Nigeria.

Methods

The study was conducted among 62 small and medium scale enterprises in Asaba, Delta State, selected by stratified random sampling. The design was cross-sectional analytical. A structured interviewer-administered questionnaire was developed and completed for each enterprise. Data was analyzed using SPSS version 20.0 and presented using frequency tables and charts.

Results

The findings revealed that $22.6 \%$ and $9.7 \%$ of the SMEs had OHS policy and Joint Health and Safety Committee respectively. Furthermore, $74.2 \%$ reported they had Health and Safety Rules with only $41.3 \%$ having a written rule. None had a clinic, but $27.4 \%$ had a medical retainership which included a higher proportion of medium scale enterprise (77.8\%) $(p<0.001)$. Nine enterprises $(33.9 \%)$ made up of a higher proportion of medium scale firms $(100.0 \%)(p<0.001)$ conducted training on OHS. A higher proportion of medium enterprises $(66.7 \%)$ conducted accident reporting and investigation $(p<0.001)$.

\section{Conclusion}

There were gaps in the implementation of occupational health and safety services in majority of the enterprises with OHS-MS significantly better developed in medium enterprises. SMEDAN should ensure SMEs implement improved occupational health services, capacity building among employees on occupational health and safety management system and also, further studies on the subject matter are recommended.
\end{abstract}

Key words: occupational health, management system, safety, Delta State, Nigeria, small and medium enterprises, management systems, occupational health and safety, Asaba, Delta State, Nigeria, Africa

\section{Introduction}

Occupational health and safety management system (OHS-MS) is defined as the delivery of program components in a methodical and integrated format that work together to improve health and safety performance in an organisation. ${ }^{1}$ Provision of occupational health services is 
a key issue in small and medium enterprises (SME) and this has been adduced to paucity of resources available to the owners of the enterprises. ${ }^{2,-5}$ In Nigeria, small and medium enterprises account for $25 \%$ of the labour force, $46 \%$ of gross domestic product (GDP), and employ $70 \%$ of the industrial labour force. ${ }^{6,7}$

The legislative environment is critical to the development of occupational health practices in the nation. In Nigeria, the occupational health legislation was observed not to be SMEfriendly and the Small and Medium Enterprises Development Agency of Nigeria (SMEDAN) had set a target in 2007 to review the occupational health and safety act in Nigeria to make it more SME- friendly. ${ }^{8}$ Implementing the current legislation is difficult by SMEs as methods of OHS-MS developed for large firms are often not adaptable to the work environment in SMEs. ${ }^{9}$ Moreover, a UK-based study conducted in Sheffield to assess the occupational health services to employees, revealed that there were gaps in the provision of such services. ${ }^{10}$ Furthermore, a review of OHS-MS in Pakistan also revealed that there were significant gaps in the provision of occupational health services as majority of the SMEs do not have an identified occupational health and safety programme. ${ }^{11}$

The health status of workers in SMEs have been shown to be worse than those in larger scale enterprises. ${ }^{3}$ In a study conducted in 1996 to assess the state of occupational health services in Edo and Delta States in industrial establishment, the findings of the study revealed that there were inadequate provision of OHS among the SMEs. ${ }^{12}$ Another study conducted among beauticians in Benin City, Edo State, revealed that majority were unaware of the hazards of their trade (69.9\%) and most $(87.4 \%)$ had musculoskeletal problems. ${ }^{13}$ Furthermore, a study conducted in Benin City among welders revealed that they are inadequately provided with occupational health services. ${ }^{14}$ A similar study conducted in Taiwan among employers showed that awareness of occupational health and safety was found to be poor in SMEs. ${ }^{15}$

The Federal Government of Nigeria in the year 2014 launched the National Industrial Revolution Plan with SMEs to serve as the pivot and this necessitates a renewed focus on OHS-MS in this sector. Yet despite their economic importance and the number of employees engaged by them, SMEs have received little attention from occupational health and safety researchers. ${ }^{9,16}$ Studies on OHS-MS are needed to improve occupational health services in SMEs which serve as catalyst for employment generation, poverty reduction and economic development $^{7}$ and this can only be achieved with appropriate occupational health services to ensure workers are healthy which will in turn promote productivity.

The objective of this study was to assess the occupational health and safety management system of small and medium enterprises in Asaba, Delta State, Nigeria.

\section{Methods}

\section{Study area}

The study was conducted in Asaba, Delta State in the South South geopolitical zone of Nigeria. Small and medium enterprises in Delta State have received significant support from the administration of the state governor, Dr. Emmanuel Uduaghan with him receiving National awards for the development of SMEs.

\section{Study design}

The design was cross-sectional analytical.

\section{Study population and sample size determination}

The study units were the SMEs listed in the directory of the Delta State Ministry of Commerce and Industry. The respondents included either management staff or staffs who were knowledgeable in OHS issues. Respondents who declined were excluded from the study.

Sample size determination was computed using the Cochran (1977) formula ${ }^{17}$ for a simple proportion. $\mathrm{n}=\mathrm{Z}^{2} \mathrm{pq} / \mathrm{d}^{2}$ 


\section{Sampling method}

A panel study of the SMEs was done and there were 73 SMEs in the Asaba, listed in the directory of Delta State Ministry of Commerce. Sixty -two SMEs agreed to participate in the study.

\section{Study tool}

Data was collected using a structured questionnaire that was developed and administered to the respondents. Ethical approval was gotten from the institutional ethical review committee and the survey was anonymous to ensure privacy. Individual informed consent was obtained from each respondent.

\section{Data analyses}

Data was analyzed using IBM SPSS version 20.0 and presented using frequency tables. Further analysis was done with the aid of Compare ${ }^{2}$ Program in Win Pepi version 11.0. Test of association was done using Chi square test,(Fishers test) Odds ratios (ORs) and their corresponding $95 \%$ confidence interval (CI) were also computed. Small enterprises served as the referent category and was assigned a null value of 1.00 in computing the ORs. Exclusion of the null value of 1.00 from the $95 \%$ CIs of ORs and $p$ value $<0.05$ was assumed to be statistically significant.

\section{Results}

Table 1: Distribution of SMEs

\begin{tabular}{|l|l|l|}
\hline Type of Industry & \multicolumn{2}{|l|}{ Category of Enterprises n (\%) } \\
\hline & Small & Medium \\
\hline Business services & $10(18.9)$ & $0(0.0)$ \\
\hline Oil and gas & $10(18.9)$ & $0(0.0)$ \\
\hline General & $10(18.9)$ & $0(0.0)$ \\
\hline Building and construction & $9(17.0)$ & $1(11.1)$ \\
\hline Hospitality & $8(15.1)$ & $2(22.2)$ \\
\hline Information technology & $3(5.6)$ & $0(0.0)$ \\
\hline Clothing and textile & $2(3.8)$ & $1(11.1)$ \\
\hline Manufacturing & $1(1.9)$ & $5(55.5)$ \\
\hline Total & $\mathbf{5 3 ( 1 0 0 . 0 )}$ & $\mathbf{9 ( 1 0 0 . 0 )}$ \\
\hline
\end{tabular}

Table 1 showed that a large proportion of medium enterprises $(55.5 \%)$ were in the manufacturing sector of the economy. A majority (77.8\%)of medium enterprises had an occupational health and safety policy compared to $13.2 \%$ of small enterprises and this difference was statistically significant $(\mathrm{p}<0.001)$.

Table 2: Pattern of OHSMS in SMEs

\begin{tabular}{|c|c|c|c|c|}
\hline \multirow[t]{2}{*}{ Variables } & \multicolumn{3}{|c|}{ Category Of Enterprises $n_{0}(\%)$} & \multirow[t]{2}{*}{ OR $(95 \% \mathrm{CI})$} \\
\hline & Small & Medium & p value/ $\chi^{2}$ & \\
\hline \multicolumn{5}{|c|}{ Accident Reporting and Investigation } \\
\hline No & $45(84.9)$ & $3(33.3)$ & $\chi^{2}=11.705$ & 1.00 \\
\hline Yes & $8(15.1)$ & $6(66.7)$ & $\mathrm{p}=0.001$ & $11.25(1.84-79.54)$ \\
\hline \multicolumn{5}{|c|}{ Medical Retainership } \\
\hline No & $43(81.1)$ & $2(22.2)$ & $\chi^{2}=13.416$ & 1.00 \\
\hline Yes & $10(18.9)$ & $7(77.8)$ & $\mathrm{p}<0.001$ & $15.05(2.26-159.76)$ \\
\hline \multicolumn{5}{|c|}{ Written Work Procedure } \\
\hline No & $42(79.2)$ & $3(33.3)$ & $\chi^{2}=8.149$ & 1.00 \\
\hline Yes & $11(20.8)$ & $6(66.7)$ & $\mathrm{p}<0.004$ & $7.64(1.32-52.59)$ \\
\hline
\end{tabular}


South American Journal of Public Health

Special Edition May 2016

\begin{tabular}{|l|l|l|l|l|}
\hline No & $41(77.4)$ & $0(0.0)$ & $\chi^{2}=20.555$ & 1.00 \\
\hline Yes & $12(22.6)$ & $9(100.0)$ & $\mathrm{p}<0.001$ & $\infty(5.52-\infty)$ \\
\hline OHS Policy \\
\hline No & $46(86.8)$ & $2(22.2)$ & $\chi^{2}=18.349$ & 1.00 \\
\hline Yes & $7(13.2)$ & $7(77.8)$ & $\mathrm{p}<0.001$ & $3.906(1.15-13.32)$ \\
\hline Joint Health and Safety Committee \\
\hline No & $48(90.6)$ & $8(88.9)$ & $\chi^{2}=0.025$ & 1.00 \\
\hline Yes & $5(9.4)$ & $1(11.1)$ & $\mathrm{p}=0.875$ & $1.20(0.02-13.01)$ \\
\hline Employee Orientation Programme \\
\hline No & $25(47.2)$ & $0(0.0)$ & $\chi^{2}=7.114$ & 1.00 \\
\hline Yes & $28(52.8)$ & $9(100.0)$ & $\mathrm{p}=0.008$ & $\infty(1.55-\infty)$ \\
\hline
\end{tabular}

Table 2 shows that while $66.7 \%$ of medium enterprises conduct accident reporting, $15.1 \%$ of small enterprises practice same and this difference was significant $(\mathrm{p}=0.001)$. More than three quarters of medium enterprises have a medical retainership significantly more than $18.9 \%$ of small enterprises $(p<0.001)$. All medium enterprises conduct occupational health and safety training for their employees compared to $22.6 \%$ of small scale enterprises ( $p<$ $0.001)$

Over three quarter $(77.8 \%)$ of medium enterprises had a written OHS policy compared to over a tenth $(13.2 \%)$ of small enterprises and this difference was significant $(\mathrm{p}<0.001)$. Over a tenth $(11.1 \%)$ of medium enterprises and $9.4 \%$ of small enterprises had a joint health and safety committee $(\mathrm{p}=0.875)$

\section{Discussion}

The absence of an OHS policy among majority of small enterprises suggests a lack of organisational commitment to occupational health and safety. The proportion of SMEs that had a joint health and safety committee was far less than findings in a US based study $(37.7 \%) .{ }^{18}$ This may imply poor management desire to engage employee input in occupational health issues and reveals significant gaps in the implementation of the occupational safety and health act among SMEs. Workers are more likely to abide by occupational health rules and regulations if they are carried along. Furthermore the absence of employee input in the formulation and implementation of OHSMS policies in SMEs may skew the policies in favour of management and may not adequately protect the interest of the workers.

The proportion of enterprises with training in OHS for workers was similar to findings in Norway among small enterprises ( $<20$ employees), while $73.4 \%$ of SMEs in the US conduct worker safety training. ${ }^{5,18}$ Given that majority of small enterprises do not conduct employee orientation programme or OHS training, suggests that workers may not be knowledgeable of the hazards they face, and consequently, may be left to find out the harm inherent in their occupations at the cost of their lives.

The absence of written procedures and accident reporting and investigation in most of the small scale enterprises may imply a lack of safety culture and adequate data collection in those enterprises. The ILO has stated that improving reporting systems for occupational accidents and diseases is an increasingly important challenge in many African countries. ${ }^{19-21}$ Adequate data collection and reporting systems on occupational accidents and diseases forms the bedrock of proper decision making and planning for prevention and control.

None of the SMEs had a clinic, and the widespread use of retainer clinics may be the common practice given the available resources. This may often and only avail the employees of general medical care rather than occupational health services and suggests a need for group/area occupational health services.

Given the findings of OHS-MS in SMEs suggests that workplace inspections have been ineffective at improving the OHS in these enterprises. Information from Ministry of Labour, indicate that Factories Inspectors are few and ineffective, because they have not been provided the enabling environment to function properly. ${ }^{22}$ It is the responsibility of factory 
inspectors to carry out inspection of factories at the state level and report their findings to the Federal Ministry of Labour. Factory inspectors complained in a previous study that they have not being given the requisite training to perform their duties. However, there are only 60 factory inspectors to cover the entire country of Nigeria and this is grossly inadequate for a teeming population of 170 million. Limited number of factory inspectors coupled with the absence of political will to implement the existing laws is partly responsible for the lack of development of occupational health services in SMEs. ${ }^{22}$ It may also be alluded to that most countries and industries have not come to realise that occupational health and practices is a crucial determinant of national development. ${ }^{16}$

The absence of the majority of the elements of OHS-MS may also suggest a poor capacity of the management of SMEs to provide occupational health services to their employees. Findings of poor OHS provision in SMEs were similar to findings in a study conducted about two decades ago ${ }^{12}$ indicating that there is an absence of significant change regarding situation is still much the same. Such findings suggest that there are significant gaps between research findings in the sector and policy development and implementation which are tell-tale signs that similar research findings have not impacted on the implementation of occupational health services. Unless supervising ministries engage the academia and utilize available research findings to influence policy action, significant improvement in occupational health practice may not be achieved.

\section{Conclusion}

This study has revealed gaps in the implementation of occupational health and safety management systems in majority of the enterprises with OHS-MS significantly better developed in medium scale enterprises. SMEs have a deficient OHS-MS which is a much needed tool to deliver basic occupational health and safety services to their employees.

It is therefore recommended that SMEDAN should make capacity building of the management of SMEs compulsory as this is pertinent to deliver OHS to their employees. There is also a need for active collaboration, networking and cooperation among small and medium scale enterprises, especially among those in similar industry to develop OHS services.

Capacity building among employees on occupational health and safety management system so that they can begin to demand such services from their employers in line with best practices all over the world.

Professional occupational health professional groups such as Association of Public Health Physicians of Nigeria (APHPN) and Society of Occupational and Environmental Physicians of Nigeria (SOEHPON) should promote and engage the small and medium entrepreneurs to develop group/area occupational health practice.

Necessity of bridging the gap between research and policy by all stakeholders.

\section{References}

[1.] Asuzu MC. The development and state of health and safety in the workplace in West Africa: perspectives from Nigeria. West Afri. J Med. 1996: 15(1):36-44.

[2.] Bonita R, Beaglehole R, KjellstomT. Basic Epidemiology. Second edi. Geneva: World Health Organization; 2006.

[3.] Bull N, Riise T, Moen BE. Work-related injuries and occupational health and safety factors in smaller enterprises- a prospective study. Occupational Medicine $2002 ; 52(2): 70-74$.

[4.] Bradshaw LM, Curran AD, Eskin F, Fishwick D. Provision and perception of occupational health in small and medium-sized enterprises in Sheffield, UK. Occup Med. 2001; 51(1): 39-44.

[5.] Ekwujuru P (2013). MSMEs contribute $47 \%$ to Nigeria's GDP- SMEDAN. The Vanguard Newspaper, 13th October. Available from www.vanguardngr.com.Cited 13th February, 2014.

[6.] Gallagher C, Underhill E, Rimmer M (2001). OHS Management Systems: A Review of their Effectiveness in Securing Healthy \& Safe Workplaces . Available from 
South American Journal of Public Health

Special Edition May 2016

http://www.safeworkaustralia.gov.au/sites/SWA/about/Publications/Documents/127/OHSManagement Systems_ReviewOfEffectiveness_NOHSC_2001_Arch ivePDF.pdf.Cited 1st March, 2014.

[7.] Hoshuyama T, Hino Y, Kayashima K, Morita T, Minami M, Sakuragi S, et al. Inequality in the health status of workers in small-scale enterprises. Occupational Medicine 2007;57:126-130.

[8.] Hu SC, Lee CC, Shiao JSC, Guo YL. Employers' awareness and compliance with occupational health and safety regulations in Taiwan. Occup. Med. 1998; 48(1): 17-22. 12

[9.] Isah EC, Asuzu MC, Okojie OH. Occupational health services in manufacturing industries in Nigeria. Occup Med (Lond). 1996 Oct; 46(5):333-6.

[10.] Isah EC, Okojie OH. Occupational Health Problems of Welders in Benin City, Nigeria. Journal of Biomedical Sciences 2006; 5 (1): 64-69

[11.] Kadiri IB. Small and medium scale enterprises and employment generation: The role of finance. Kuwait chapter of Arabian journal of business and management Review 2012 ;1(9):9-88.

[12.] Kawakami T. Strengthening occupational accident and disease reporting systems. African Newsletter on Occupational Health and Safety 2010; 20 (3): 47.

[13.] Kalejaiye PO. Occupational health and safety: Issues, challenges and compensation in Nigeria. Peak Journal of Public Health and Management 2013; 1 (2): 16-23.

[14.] Lentz T J, Wenzl TB. Surveillance: Small Businesses with High Fatality Rates: Assessment of Hazards and Their Prevention. Journal of Occupational and Environmental Hygiene 2006; 3(2):9-14.

[15.] Mizoue T, Higashi T, Muto T, Yoshimura T, Fukuwatari Y. Activities of an occupational health organization in Japan., in special reference to services for small- and medium-scale enterprises. Occup. Med. 1996: 46 (1): 12-16.

[16.] Matiko JM. Injury and disease reporting in Tanzania. African Newsletter on Occupational Health and Safety 2010; 20 (3): 48-50.

[17.] Okojie OH, Isah EC. Assessment of Occupational Hazards among Beauticians in Benin City. Nigerian Journal of Clinical Practice 2001 ; 4(1): 25-27.

[18.] Okojie O. System for reporting occupational diseases in Nigeria. African Newsletter on Occupational Health and Safety, 20 (3), 51-53.

[19.] Pingqing L, Fang L, Chunjing G. Occupational Health and Safety(OHS) in Small and Medium Size Enterprises (SMEs): A Primary Review. Canadian Social Science 2006 ;2(1):7-12.

[20.] Puplampu BB, Quartey SH. Key Issues on Occupational Health and Safety Practices in Ghana: A Review. International Journal of Business and Social Science. 2012 ; 3( 19): 151-156.

[21.] Small and Medium Enterprise Development Agency of Nigeria (2007). National Policy on Micro, Small and Medium Enterprises.

[21.] Shahab S. Development and Implementation of an Occupational Safety and Health Management Program for the Small- to Medium-Sized, Indigenous, Privately Owned Enterprise in Pakistan. Appl. Occup. Environ. Hyg. 1998 ; 13(12):811-816. 